\title{
EVAluATING EFFECTIVENESS FACTOR OF OBJECT Oriented Design: A Testability Perspective
}

\author{
MAHFUZUL HUdA ${ }^{1}$, Y.D.S. ARYA ${ }^{2}$, M. H. KHAN ${ }^{3}$ \\ ${ }^{1}$ Research Scholar, Department of Computer Sc. \& Engineering, Invertis University, \\ Bareilly, India \\ ${ }^{2}$ Pro -Vice Chancellor, Invertis University Bareilly, India \\ ${ }^{3}$ Associate Professor, Department of Computer Science and Engineering at IET \\ Lucknow, India
}

\begin{abstract}
Effectiveness is important quality factor to testability measurement of object oriented software at an initial stage of software development process exclusively at design phase for high quality product. It will help developer's design capability to achieve the specified functionalities, characteristics, better design quality and behavior using appropriate object oriented design (OOD) concepts and procedures. Metric based model for 'Effectiveness Quantification Model of Object Oriented Design' has been proposed by establishing the correlation between effectiveness and OOD constructs. Later 'Effectiveness Quantification Model' is empirically validated and statistical significance of the study considers the high correlation for model acceptance. The aim of this research work is to encourage researchers and developers for inclusion of the effectiveness quantification model to access and quantify software effectiveness quality factor at design time.
\end{abstract}

\section{KEYWORDS}

Effectiveness, Testability, Object Oriented Design, Design Metrics, Object Oriented Software, Software Quality Model, Software Testing, Effort Estimation.

\section{INTRODUCTION}

Effectiveness is strongly related to testability and constantly plays a key role to deliver high class, best quality and trustworthy software within time and given budget [1] [2]. It is one of the most important concepts in design for testing of software programs and components [3].According to ISO-DIS 14598 the term Effectiveness factor is defined as the capacity of the software product to enable users/developers to achieve specified goals with accuracy and completeness in a specified environment. Software design is a process in software engineering that produces a tangible model of the system and allows developers /researchers to turn your computational model into a workable algorithm to solve the problems by the help of verification and evaluation. According to ISO 9126 quality model degree of efficiency and performance characteristics of any design achieves expected functionalities by effectiveness factor [4]. It always supports developer for improved software design at early stage of software development life cycle, means design phase has positive impact on the overall testing cost and effort. Software testability always supports the testing process and facilitates the creation of better quality software within time and allotted budget [4-7].To design and develop a high quality and effective product, effectiveness plays an important role for assessment of software testability. Estimating effectiveness factor early in the

DOI : 10.5121/ijsea.2015.6104 
International Journal of Software Engineering \& Applications (IJSEA), Vol.6, No.1, January 2015

development process may greatly reduce the overall cost. Design phase plays the backbone role of any product [8]. The object oriented design concept is a suitable language which deals with real world entities for generalize productivity [9]. This study aims to produce a model to quantify quality factor at design time of development life cycle.

This paper is organized in such a, manner that it initially describes the effectiveness quality factor and then lists and describes effectiveness quantification model development with their mapping, correlation establishment and also highlights data for statistical significance of model that are important for further study. The presented model has been validated and the research paper concludes with industry utility for project ranking in conclusion section.

\section{EFFECTIVENESS FACTOR}

Effectiveness is one of the most important attribute of software quality for delivering high quality software. It is also an important quality factor to testability estimation of object oriented software at an early phase of software development life cycle. Design time is most appropriate phase to estimate quality of software, because this phase is the first step towards problem domain to solution domain [2][10-12].software quality is still a elusive and multifaceted concept, which mean different things to different users, typically the way we measure quality depends on the viewpoint we take[14].

The overall purpose of the software is to deliver quality oriented software that is effective in operation, easily approachable to user within specified time and given budget because delivering quality software is no longer an advantage, but a required factor[4][13][15]. The proposed study to evaluate software effectiveness by using the concept of software quality estimation during the initial time in development life cycle. Here research is needed to develop a structured scientific approach to ensure that software is stable, effective and high quality.

\subsection{Correlations among Quality Factor, OOD Properties and OOD Metrics}

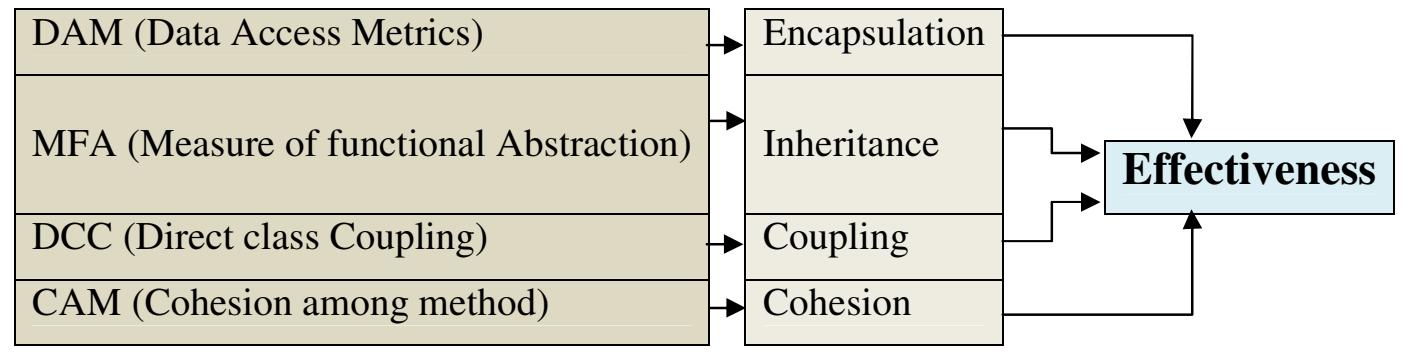

Figure 1. Effectiveness Quantification Framework of Object Oriented Design

The figure 1, describes the quantification process of effectiveness model in order to establish a multivariate model for effectiveness and OOD constructs. The values of these metrics can be easily identified by class diagram metrics. This metrics will play the role of independent variables while effectiveness will be taken as dependent variable. The quantifiable assessment of effectiveness is very helpful to achieve testability index of software design for quality product within time and given budget.

Proposed framework involves the following steps

1. Identification of object oriented design metrics that influence effectiveness at design time. 
2. Identification of factors of object oriented properties.

3. Mapping of OOD Metrics, OOD Properties, and Quality Factor.

Correlation among effectiveness factor and object oriented design metrics has been established and shown in figure-1.In order to establish a mapping between object oriented design properties and quality factor, the influence of object oriented metrics are being examined with respect to effectiveness quantification model. It was observed that each OOD metrics affect certain quality factor. As per the values of selected independent variables, namely DAM (Data Access Metrics),MFA (Measure of functional Abstraction),DCC (Direct class Coupling),CAM (Cohesion among method), the values of dependent variable ' $\mathrm{Y}$ ' can be found out by using the 'Effectiveness Quantification Model of Object oriented design' [8][14][16-18].

\subsection{Effectiveness Quantification Model Development}

It is evident from literature survey that effectiveness is not a new term; rather it has been in discussion among the industry professionals at various forums ,but there is no commonly accepted comprehensive and complete model or framework available to estimating the effectiveness of the product at design phase, that motivate to develop 'Effectiveness Quantification Model of Object oriented design', using object oriented design approach based on its internal design property at an initial stage of development life cycle.

The generic quality model (Bansiya's quality model[14]) has been considered as a basis to develop the effectiveness estimation model for OOD.This model used the low level design metrics namely Data access metrics, Measure of functional abstraction, Direct class Coupling, Cohesion among methods, to describe a range of measurement for software and defined in terms of design characteristic and also helpful for quantitative assessment of degree to which system, component or process hold a given attribute.

In order to establish a model for effectiveness, multiple linear regression techniques have been used .The proposed multivariate model takes the following form

$Y=\alpha_{0}+\alpha_{1} X_{1}+\alpha_{2} X_{2}+\alpha_{3} X_{3}+\ldots \ldots \ldots \alpha_{n} X_{n}$

Where

- $\mathrm{Y}$ is dependent variable

- $\mathrm{X}_{1}, \mathrm{X}_{2}, \mathrm{X}_{3}, \ldots . . \mathrm{X}_{\mathbf{n}}$ are independent (regressor) variables.

- $\boldsymbol{\alpha}_{1}, \boldsymbol{\alpha}_{2}, \ldots \boldsymbol{\alpha}_{\mathrm{n}}$ are the regression coefficient of the respective independent variable.

- $\boldsymbol{\alpha}_{0}$ is the regression intercept.

Effectiveness $=\left[\alpha 0 \pm(\alpha 1 *\right.$ Encapsulation $) \pm(\alpha 2 *$ Inheritance $) \pm\left(\alpha 3^{*}\right.$ Coupling $) \pm($

$\alpha 4 *$ Cohesion)]

----- eq. $(1)$

Using 'SPSS' software values of all independent variables (metrics), regression intercept and coefficient of the respective independent variables are calculated. On the basis of this approach, the multiple linear regression effectiveness model has been developed that is given in equation 2.Effectiveness factor of a class depend upon one or more number of object oriented design metrics, quality factor and object oriented design metrics may be fixed by using model 'Effectiveness Quantification Model of Object oriented design.' 
Effectiveness $=[8.783-(1.614 *$ Encapsulation $)+(11.141 *$ Inheritance $)-(.866 *$ Coupling $)-($ 6.477*Cohesion)]

\subsection{Statistical Significance of Model}

Table 1: Statistical Significance of Effectiveness Model

\begin{tabular}{|l|l|l|l|}
\hline & Mean & Std. Deviation & N \\
\hline Effectiveness & 7.5571 & 3.27229 & 7 \\
\hline Encapsulation & 0.8271 & 0.20950 & 7 \\
\hline Inheritance & 0.4600 & 0.21840 & 7 \\
\hline Coupling & 2.7457 & 2.83597 & 7 \\
\hline Cohesion & 0.4071 & 0.20500 & 7 \\
\hline
\end{tabular}

The descriptive table is very important for further research work. It gives the valuable record of descriptive statistics that are mean, standard deviation and number of samples selected for model validation.

Table 2: Examination of ANOVA ${ }^{\text {for }}$ Effectiveness Model

\begin{tabular}{|l|l|l|l|l|l|}
\hline Model (1) & Sum of Squares & Df & Mean Square & F & Sig. \\
\hline Regression & 62.611 & 4 & 15.653 & 19.129 & $0.050^{\text {a }}$ \\
\hline Residual & 1.637 & 2 & 0.818 & & \\
\hline Total & 64.247 & 6 & & & \\
\hline a. Predictors: (Constant), Cohesion, Inheritance, Encapsulation, Coupling \\
\hline
\end{tabular}

ANOVA examination for dependent variable (effectiveness) gives the result of frequency ratio (F) with degree of freedom (df).Research table 2 shows F ratio 19.129 with (4,2)degree of freedom of ANOVA examination results by experimental tryout. It also shows that effectiveness model is statistically significant at the confidence interval level of $95 \%$. 
Table 3: Coefficients and Statistical Significance of Independent Variables and Constant for Effectiveness Model

\begin{tabular}{|c|c|c|c|c|c|}
\hline \multirow[t]{2}{*}{ Model (1) } & \multicolumn{2}{|c|}{$\begin{array}{l}\text { Unstandardized } \\
\text { Coefficients }\end{array}$} & \multirow{2}{*}{$\begin{array}{l}\text { Standardized } \\
\text { Coefficients } \\
\text { Beta }\end{array}$} & \multirow[b]{2}{*}{$\mathrm{t}$} & \multirow[b]{2}{*}{ Sig. } \\
\hline & B & Std. Error & & & \\
\hline (Constant) & 8.783 & 7.048 & & 1.246 & 00.339 \\
\hline Encapsulation & -1.614 & 6.231 & -0.103 & -0.259 & 0.820 \\
\hline Inheritance & 11.141 & 2.960 & 0.744 & 3.763 & 0.064 \\
\hline Coupling & -0.866 & 0.530 & -0.751 & -1.633 & 0.244 \\
\hline Cohesion & -6.477 & 3.633 & -0.406 & -1.783 & 0.217 \\
\hline
\end{tabular}

Coefficients and statistical significance of independent variables and constant for effectiveness model prove that all the four selected metrics do the statistically significance role at a significance level of .005 it indicates that the error probability is 1 in 5000, which is a very significant correlation between the two sets of data.

Table 4: Model Summary for Effectiveness Model

\begin{tabular}{|l|l|l|l|l|l|l|l|l|l|}
\hline Mod & $\mathrm{R}$ & $\mathrm{R}$ & Adjusted & Std. Error & \multicolumn{2}{l}{$\begin{array}{l}\text { Change Statistics } \\
\text { el }\end{array}$} & Square & R Square & the \\
\cline { 4 - 8 } & & & & $\begin{array}{l}\text { R Square } \\
\text { Estimate }\end{array}$ & Change & F Change & $\begin{array}{l}\text { df } \\
1\end{array}$ & $\begin{array}{l}\text { df } \\
2\end{array}$ & $\begin{array}{l}\text { Sig. F } \\
\text { Change }\end{array}$ \\
\hline 1 & $0.987^{\mathrm{a}}$ & 0.975 & 0.924 & 0.90458 & 0.975 & 19.129 & 4 & 2 & 0.050 \\
\hline
\end{tabular}

Summary table 5 for Effectiveness Quantification Model proves that all the four selected metrics are statistically significant at confidence level of $95 \%$.

\section{Empirical Validation of Effectiveness Factor Model}

This section of work proves that how significant proposed study, where metrics and model are able to estimate the effectiveness quality index of object oriented design at design time. The empirical validation is important phase of research to evaluate the proposed effectiveness quality model for high level acceptability and appropriate execution. Empirical validation is the fine approach and best practice for claiming the model acceptance [19]. To justify claiming approach for acceptance of model, an experimental validation of the proposed effectiveness quantification model at design time has been carried out using samples.

\subsection{Data Set for Fifteen Projects}

The data is taken from this model is from various versions of two famous windows application frameworks, Microsoft foundation class (MFC) and Borland object windows library (OWL), where five publicly released versions of Microsoft foundation class (MFC 1.0, MFC 2.0, MFC 3.0, MFC 4.0, MFC 5.0) [14] and four versions of Borland object windows library (OWL 4.0, OWL 4.5, OWL 5.0, OWL 5.2) [14]) were taken for empirical validation to claim the model acceptance. In view of this fact, an experimental validation of the proposed model for effectiveness evaluation has been carried out using sample tryouts. In order to validate proposed 
International Journal of Software Engineering \& Applications (IJSEA), Vol.6, No.1, January 2015

effectiveness quantification model, the value of metrics are available by using [14] data set for following 15 projects in Table 5.

Table 5. Known and Calculated Effectiveness Index Values and Ranking for 15 Projects

\begin{tabular}{|l|l|l|l|l|l|l|}
\hline Project & $\begin{array}{l}\text { Calculated } \\
\text { Index }\end{array}$ & $\begin{array}{l}\text { Calculated } \\
\text { Ranking }\end{array}$ & $\begin{array}{l}\text { Known } \\
\text { Index }\end{array}$ & $\begin{array}{l}\text { Known } \\
\text { Ranking }\end{array}$ & $\mathbf{d}^{\mathbf{2}}$ & $\mathbf{r}_{\mathbf{s}}$ \\
\hline P1 & 3.85443 & 3 & 4.822 & 5 & 0 & 0.992857 \\
\hline P2 & 4.39833 & 4 & 6.614 & 9 & 25 & 0.955357 \\
\hline P3 & 4.52761 & 5 & 6.684 & 10 & 49 & 0.955357 \\
\hline P4 & 8.25626 & 11 & 0.882 & 1 & 64 & 0.821429 \\
\hline P5 & 7.41538 & 9 & 1.162 & 2 & 36 & 0.9125 \\
\hline P6 & 2.22377 & 1 & 2.154 & 3 & 4 & 0.992857 \\
\hline P7 & 4.8597 & 6 & 6.6 & 8 & 4 & 0.992857 \\
\hline P8 & 7.692 & 10 & 5.8 & 6 & 25 & 0.971429 \\
\hline P9 & 12.5184 & 15 & 8.2 & 14 & 1 & 0.998214 \\
\hline P10 & 10.0897 & 14 & 6 & 7 & 49 & 0.9125 \\
\hline P11 & 9.251 & 13 & 7.6 & 12 & 1 & 0.998214 \\
\hline P12 & 8.265 & 12 & 8.4 & 15 & 9 & 0.983929 \\
\hline P13 & 5.204 & 7 & 7 & 11 & 16 & 0.971429 \\
\hline P14 & 7.3989 & 8 & 8 & 13 & 9 & 0.955357 \\
\hline P15 & 3.75315 & 2 & 3.8 & 4 & 4 & 0.992857 \\
\hline
\end{tabular}

The known effectiveness ranking for given projects (P1 to $\mathrm{P} 15)$ are shown in above table 5.Using the same sets of data for given fifteen software projects from P1 to P15,effectiveness index was calculated using the proposed 'Effectiveness Quantification Model of Object oriented design' and index values are shown in the table 5 .

Table 6 : Calculated Effectiveness Index Values and Ranking for 15 Projects and Project Acceptance under Charles Spearman's Rank Correlation Coefficient

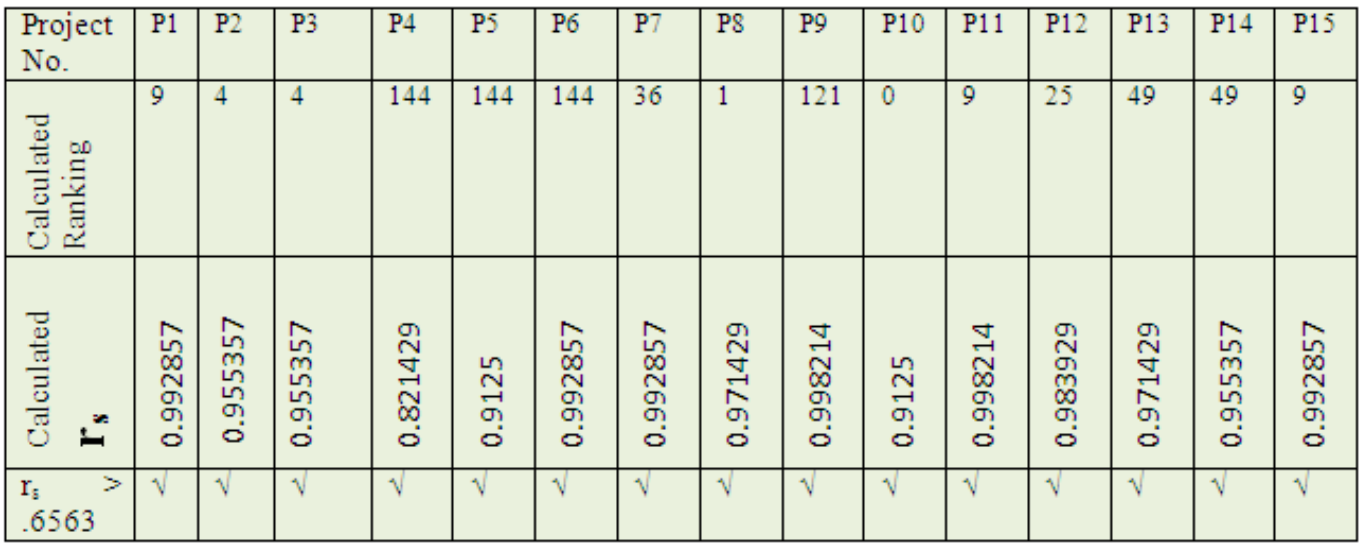

On the basis of these empirical validation results, the Effectiveness Index of all fifteen software projects are ranked 1 through 15 based on increasing effectiveness index values by every validation process of project as shown in table 6 . 
International Journal of Software Engineering \& Applications (IJSEA), Vol.6, No.1, January 2015

\subsection{Statistical analysis of Effectiveness Quantification Model of Object oriented design}

Charles Spearman's Rank Correlation Coefficient $\left(\mathbf{r}_{\mathbf{s}}\right)$ was used to test the significance of correlation between calculated index values of effectiveness by Effectiveness Quantification Model of Object oriented design and its known index values. The ' $\mathbf{r}_{\mathbf{s}}$ ' was calculated using the following formula

$$
r_{s}=1-\frac{6 \sum d^{2}}{n\left(n^{2}-1\right)} \quad-1.0 \leq r_{s} \leq+1.0
$$

Where

- $\mathbf{r}_{\mathrm{s}}$ is coefficient of Rank Correlation

- $\mathrm{d}$ is the difference between calculated index values and known values of effectiveness.

- $\mathrm{n}$ is the number of software projects for experiment. (In this research $\mathrm{n}=15$ software projects).

- $\quad \sum$ is notification symbol, significance 'The Sum'

The correlation values between calculated effectiveness index ranking using Effectiveness Quantification Model of Object oriented design and known effectiveness ranking are shown in table 6. Pairs of these values with correlation values $\mathbf{r}_{\mathbf{s}}[ \pm .6563]$ are checked in the table 6.Study results have proved that the correlation is acceptable with high degree of confidence that is 99\%.Therefore research is concluded without any loss of generality the 'Effectiveness Quantification Model of Object oriented design' because estimation values are more reliable and valid in the context. However the research needs to be standardized with a larger experimental tryout for better acceptability and utility.

\section{Conclusion}

This paper has developed an efficient model for effectiveness quantification through object oriented design constructs using the technique of multiple linear regressions between effectiveness factor and metrics and the assessment of effectiveness factor in OOD has been validated using structural and functional information from object oriented software. This paper also validates the quantifying ability of presented model. That validation analysis on this research work proves that proposed effectiveness quantification model is highly acceptable, more practical in nature and helps the software industry in project ranking.

\section{ACKNOWLEDGEMENTS}

First and foremost, I would like to express my sincere gratitude to my supervisor Prof. Dr. YDS Arya \& Co-supervisor Assoc. Prof. Dr. M H Khan for the continuous support of my PhD study and research, motivation, enthusiasm. Their guidance helped me in all the time of research. Last but not the least; I would like to thank my parent for their patience, understanding and support that drive me to complete my study. 
International Journal of Software Engineering \& Applications (IJSEA), Vol.6, No.1, January 2015

\section{REFERENCES}

[1] Binder, Robert V. "Design for testability in object-oriented systems." Communications of the ACM 37.9 (1994): 87-101.

[2] Mahfuzul Huda, Dr.Y.D.S.Arya, and Dr.M. H. Khan. "Measuring Testability of Object Oriented Design: A Systematic Review.” International Journal of Scientific Engineering and Technology, Vol. 3, Issue 10, pp: 1313-1319 Oct, 2014

[3] Sharma, M., \& Mall, R. (2009). Automatic generation of test specifications for coverage of system state transitions. Information and Software Technology, 51(2), 418-432. doi:10.1016/j.infsof.2008.05.002.

[4] ISO, "ISO/IEC 9126-1: Software Engg.-Product Quality-Part-1: Quality Model”, Geneva, Switzerland, 2001

[5] IEEE Press, "IEEE Standard Glossary of Software Engineering Technology,"ANSI/IEEE Standard 610.12-1990, 1990.

[6] Briand, L. C., Labiche, Y., \& He, S. (2009). Automating regression test selection based on UML designs. Information and Software Technology, 51(1), 16-30. doi:10.1016/j.infsof.2008.09.010.

[7] J Voas and Miller , "Improving the software development process using testability research", Proceedings of the 3rd international symposium on software Reliability Engineering , p. 114--121, October, 1992, RTP, NC, Publisher: IEEE Computer Society.

[8] Singh, Y., \& Saha, A. (2010). Improving the testability of object oriented software through software contracts. ACM SIGSOFT Software Engineering Notes, 35(1), 1. doi:10.1145/1668862.1668869.

[9] Suhel Ahmad Khan, \& Raees Ahmad Khan, 'Object Oriented Design Complexity Quantification Model', C3IT-2012, Procedia Technology 4 (2012) 548 - 554.

[10] Zheng, W., \& Bundell, G. (2008). Contract-Based Software Component Testing with UML Models. Computer Science and its Applications, 2008. CSA '08. International Symposium on, 978-0-7695(13 - 15 October 2008), 83-102.

[11] Samar Mouchawrab ,Carleton University, Technical Report SCE-05-05 ,2005

[12] Khan, R. A., \& Mustafa, K. (2009). Metric based testability model for object oriented design (MTMOOD). ACM SIGSOFT Software Engineering Notes, 34(2), 1. doi:10.1145/1507195.1507204.

[13] Abdullah, Dr, Reena Srivastava, and M. H. Khan. "Testability Measurement Framework: Design Phase Perspective."International Journal of Advanced Research in Computer and Communication Engineering Vol. 3, Issue 11, Pages 8573-8576 November 2014

[14] Jagdish Bansia, "A Hierarchical Model for Object Oriented Design Quality Assessment", IEEE Transaction of Software Engineering, Volume 28, No. 1, January 2002, and pp: 4-17

[15] M. Nazir, Khan R A \& Mustafa K. (2010): A Metrics Based Model for Understandability Quantification, Journal of Computing, Vol. 2, Issue 4, April 2010, pp.90-94

[16] Abdullah, Dr, Reena Srivastava, and M. H. Khan."Modifiability: A Key Factor To Testability", International Journal of Advanced Information Science and Technology, Vol.26, No.26, Pages 62-71 June 2014.

[17] Genero M., J. Olivas, M. Piattini and F. Romero, "A Controlled Experiment for Corroborating the Usefulness of Class Diagram Metrics at the early phases of Object Oriented Developments", Proceedings of ADIS 2001, Workshop on decision support in Software Engineering, 2001.

[18] Shyam R. Chidamber, Chris F. Kemerer, "Towards A Metrics Suit for Object Oriented Design", OOPSLA, ACM, 1991, pp.197-211.

[19] Kout, A., Toure, F., \& Badri, M. (2011). An empirical analysis of a testability model for objectoriented programs. ACM SIGSOFT Software Engineering Notes, 36(4), 1. doi:10.1145/1988997.1989020. 
International Journal of Software Engineering \& Applications (IJSEA), Vol.6, No.1, January 2015

\section{Authors}

Mahfuzul Huda, he is pursing $\mathrm{PhD}$ in the field of software engineering from Invertis University, Bareilly, India. He has more than 7 year of teaching \& research experience. He is currently working in the area of Software Testability in Object Oriented Design. He has also published \& presented papers in refereed journals and conferences.

Dr. Y.D.S. Arya, he is currently working as Pro - Vice Chancellor, Invertis University, India, Dr. Arya obtained M.Tech. \& PhD Degree in Computer Science and Engineering from IIT Kanpur. He has more than 31 years of experience in teaching and programming. He has developed some software packages and has contribution in the Solaris Kernel 9.0 parameters development. He has worked with IIT Kanpur, Sun Microsystems, San Francisco, Ca, USA and Fujitsu at Numazu Company, Japan.

Dr. M. H. Khan Associate Professor, Department of Computer Science and Engineering at IET Lucknow, India. Obtained his MCA degree from Aligarh Muslim University (Central University) in 1989 .Later he did his PhD from Lucknow University. He has more than 26 years of experience in teaching and programming. His area of research is Software Engineering. Dr. Khan published numerous articles, several papers in refereed journals and

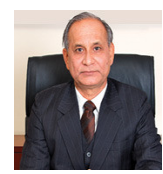
conferences. 